\title{
Exploration on Concurrent Engineering Based Quality and Development
}

\author{
Subodh Rakshit ${ }^{1}$, Siddhant $\operatorname{Yadav}^{2}$, Dr. Prashant S H ${ }^{3}$ \\ ${ }^{1,2}$ Research Scholars, Dept. of Mechanical Engineering, Sir M. Visvesvaraya Institute of Technology, Bengaluru, \\ Karnataka, India \\ ${ }^{3}$ Assistant Professor, Dept. of Mechanical Engineering, Sir M. Visvesvaraya Institute of Technology, Bengaluru, \\ Karnataka, India
}

\begin{abstract}
Concurrent Engineering (CE), as firms compete on the international market, has become increasingly crucial. The main characteristics for a successful firm are reduced time in product creation, improved product quality, cheap production cost and client requirements. Many firms employ a systematic method, i.e. Competitive engineering, for the manufacture of great products. The basic concepts and techniques of CE are used to ensure a smooth and efficient product development process, starting from the market research, by suggesting certain adjustments.
\end{abstract}

Keywords: Concurrent Engineering, Product Development Process, Product Quality, Production Cost, Production Time.

\section{INTRODUCTION}

Concurrent engineering is an advanced manufacturing technology in modern product design and development, with compact and systematic method of product design and its corresponding process (including manufacturing process and supporting process) [1,4]. With the growth of computing as a major element of design and production engineering, concurrent engineering methodologies have superseded sequential and simultaneous product design and development processes. With the use of concurrent engineering and PLM methods, the design methodology has evolved substantially since the 1990s. For an adequate competitive market reaction, industrial designers have started preferring simultaneous engineering using CAD-CAM at the same time [2].The basic principle of $\mathrm{CE}$ is that the proper product may be taken within the required time frame by decreasing costs and utilising enough materials and equipment from the suppliers, who produce the product when necessary. In the last 30 years, CE provides production in many sectors worldwide and no one company can alter its product development process, integrate its numerous inter and intra-organizations into a serial or simultaneous activity [5]. Informatics, process and collaboration, Concurrent Engineering included these three elements. Two principles are the fundamental grounds for CE. Firstly, the notion of taking into consideration in early design phases all the components of the product life cycle, ranging from function, manufacturability, assembly, testing, maintenance difficulties, environmental effect and ultimately disposal and recycling. Secondly, the previous design actions should all occur simultaneously, i.e. simultaneously. The goal is to substantially enhance productivity and product quality by being concomitant in those operations [10].

\section{LITERATURE REVIEW}

A CE research reveals that the application of CE in industry reduces the number of design modifications by $40 \%$ to $70 \%$ and the size of waste and rework by $75 \%$ [1,7]. The CE philosophy was only discussed in recent decades from the beginning of the twentieth century, but it has only become the first approach in product development thanks to the rapid development of science and technology and the increasing interdisciplinary nature of the current technical challenges $[1,14]$.

Some advanced companies in the USA have incorporated CE technology to their processes of product development and gained substantial advantages: $55 \%$ less market time, $70 \%$ better asset return and an average of $35 \%$ higher quality $[9,10]$. By utilising conceptual for concurrent training and research, they have shown that the benefits are saved time (the school student spent five weeks), greater quality (10 was attained), lowered costs (from $\$ 120$ to $\$ 50$ per part), and taught a new set of CE-literate engineers most crucially [1,12].

Pawar et al. proposed a novel approach and tool for the regeneration of organisational procedures and structures for a CE environment based on a process modelling and analytic technique [13]. More research still need to be conducted to address or establish a broader approach for CE designers. 


\section{International Advanced Research Journal in Science, Engineering and Technology}

Vol. 8, Issue 6, June 2021

DOI: $10.17148 /$ IARJSET.2021.8693

\section{CONCURRENT ENGINEERING}

The mix of design, production and support processes is concurrent engineering (CE). CE is a management concept and a set of operational principles that lead an expedited successful completion of a product development process. The whole CE concept is based on a single yet powerful premise which supports the inclusion of downstream issues into the development process' upstream phase. This would result in faster development time, better product quality and less development expenses [10]. It focuses systematically and simultaneously on the construction of a product or method that should educate all people in the first palace. Due to the rising significance of speed to market, concurrent engineering has been the standard method for new product development (NPD) throughout the last twenty years, the simultaneous implementation of dependent product development phases [9].

The objective of concurrent engineering is:

a) Shorten the interim time to identify a product concept and finalize product delivery.

b) Minimize the cost of design goods of high quality.

c) Subsequent reduction in design modifications.

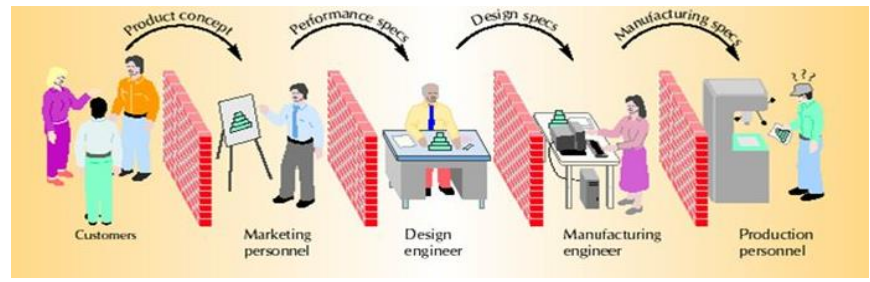

Fig. 1. Traditional Process

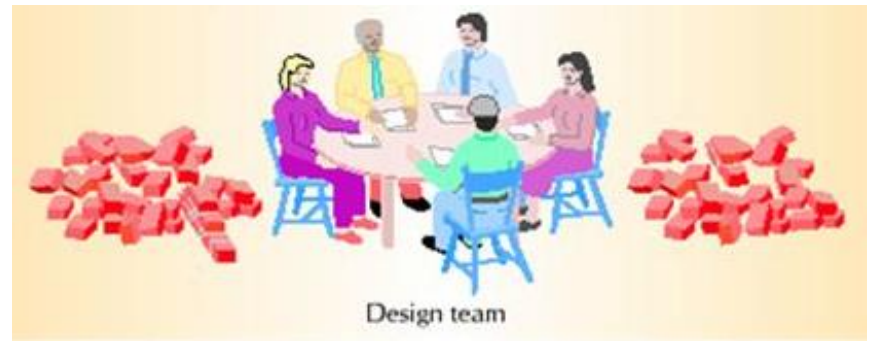

Fig. 2. Concurrent Engineering Process

\section{GOALS OF CONCURRENT ENGINEERING}

The objective is to enhance quality, minimise production costs and time. The literature contains numerous goals and motivations of contemporary engineering. The company's objectives are mentioned below:

a) Increased competition.

b) Enhanced profits.

c) Increased sales and new product earnings.

d) Reduce time to market for new products.

e) Reduce costs of human resources and capital.

f) Preserve and enhance the quality of the product

g) Making use of knowledge and experience

h) Close departmental integration and team spirit promotion.

The achievement of the above-mentioned objectives can improve their productivity and meet client demands and market demand. The intricacy of the product and its market worth are elements that each firm has to consider in order to achieve its objectives. These three problems must be monitored:

a) Lower product costs across the whole life cycle.

b) Better quality of the product

c) Current market time. 


\section{International Advanced Research Journal in Science, Engineering and Technology}

Vol. 8, Issue 6, June 2021

DOI: $10.17148 /$ IARJSET.2021.8693

\section{SEQUENTIAL VS. CONCURRENT ENGINEERING}

Sequential engineering is also called serial engineering which may be defined as information when the product is created for the design department. The information is sent. Different department functions are divided like design in sequence engineering. The prototype model will be checked for example, by simulation and other services, and if modifications occur, the cost of the product increases as well as manufacturing time increases. If market demand and product necessity cannot change this, then both product quality and product life are adversely affected. A flow diagram of sequential engineering is shown in the figure.

\begin{tabular}{|c|c|c|c|c|c|c|}
\hline $1 \longrightarrow$ & 2 & $\longrightarrow$ & $3 \longrightarrow$ & $4 \longrightarrow$ & $\longrightarrow$ & 6 \\
\hline $\begin{array}{l}\text { Market } \\
\text { investigation }\end{array}$ & & $\begin{array}{l}t \text { design } \\
\text { ation }\end{array}$ & $\begin{array}{l}\text { Conceptual } \\
\text { design }\end{array}$ & $\begin{array}{l}\text { Detail } \\
\text { design }\end{array}$ & Manufacture & Salc \\
\hline
\end{tabular}

Fig. 3. Serial Engineering Product Development Process Steps

The SE is a one-way procedure that cannot be redone on the same basis once the project has been completed. Concurrent and sequential product development typically comprises seven activity categories:

a) Define objectives.

b) Planning of the product.

c) Design.

d) Process planning of production.

e) Production.

f) Production and installation.

g) Delivery.

There are interactions between separate groups or activities in the concurrent product development, but there are no interactions in sequential product development. CE deals with several criteria such as manufacturing, testing and serviceability as well as customer performance, dimensions, weight and cost during its development phase during the design process. A flow diagram is as shown in the following figure.

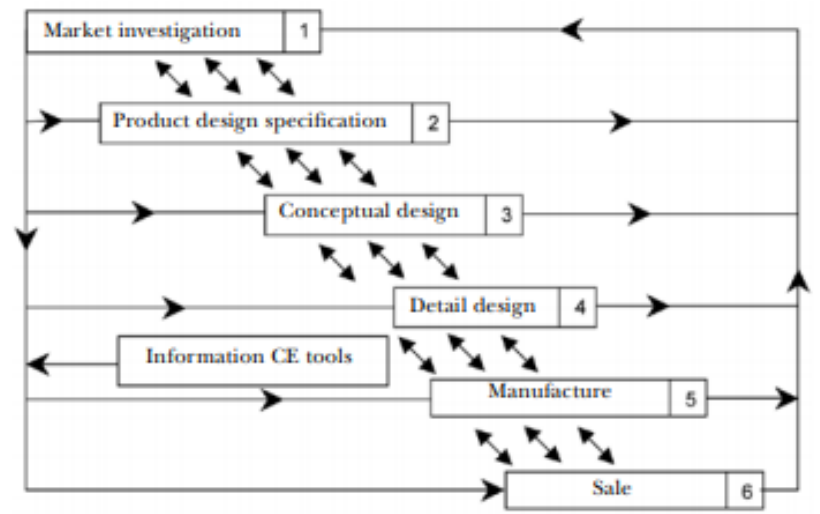

Fig. 4. CE Product Development steps

Without well-organized teamwork, concurrent engineering is not feasible. Team work is an essential component of CE since it represents the means to integrate organisations. Team work requirements are:

a) Flexible, unexpected and ongoing cooperation.

b) Flexible responsibilities to achieve objectives.

c) Communication through information exchange.

d) Capacity to compromise.

e) Consensus to dispute.

f) Reconciliation with our linked work.

g) Consistent improvements to enhance productivity and minimize process time.

\section{IMPLEMENTATION OF CE}

Three main areas addressed by implementation of Concurrent Engineering are: people, process, and technology. It necessitates significant organisational changes since it necessitates the integration of people, business procedures, and technology and relies on cross-functional collaboration and teamwork rather than the old hierarchical structure [1]. The 
Vol. 8, Issue 6, June 2021

DOI: $10.17148 /$ IARJSET.2021.8693

development of teams is one of the most important people issues. Collaboration is expected rather than individual effort, and shared information is essential for success. Members of the team must be willing to work across departments, collaborate, and think and learn on a regular basis. The leader's duty is not to tell the other team members what to do, but to provide the fundamental base and to encourage change.

Training addressed at getting people to work together in team plays an important role in the successful implementation of Concurrent Engineering. According to Pawar [13] there are seven steps to implementation of CE in any organization.

These are as follows [1] :

1. Develop a top management approach.

2. Assess the present state of the company through the use of specific evaluation tools like benchmarking, surveys and performance measurements.

3. Establish a funded firm to raise awareness of CE technique and provide associated training for CE implementation.

4. Improved priorities based on the evaluation results of step 2.

5. Plan for change with the participation of every manager, define milestones/targets and analyse resources for the CE project

6. Enhance the situation

7. Enforcement support.

These seven phases are followed by a repeated cycle since continual improvement is needed to adopt CE.

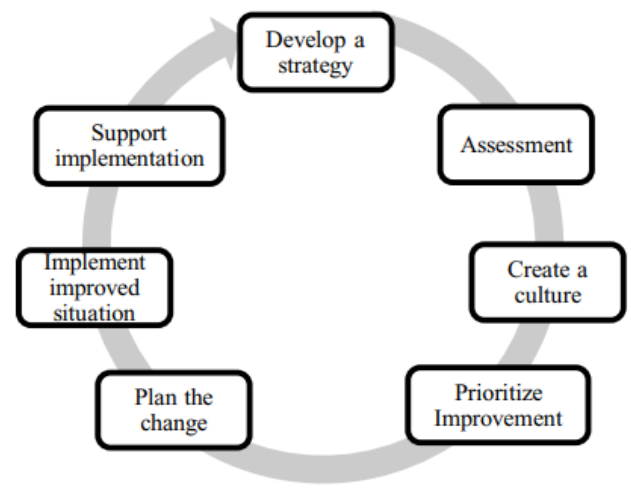

Fig. 5. Implementation of CE Steps

Several CE implementation issues in any company. These obstacles are:
a. Lack of knowledge
b. Lack of communication
c. Inappropriate structure of organisation
d. Lack of CE approach knowledge
e. Culture of businesses not supported

\section{PRINCIPLES OF CE:}

\subsection{People}

We have to consider the aspects stated below for successful installation of Concurrent Engineering:

\subsubsection{Teamwork}

The core feature of CE is teamwork. The teamwork focuses on human connections, cooperation, negotiation and decisionmaking collaboration. Teamwork is an essential component of CE since it is a way to integrate business.

\subsubsection{Multidisciplinary Teams}

$\mathrm{CE}$ relies on a team to produce multi-disciplinary products. The successful application of the CE involves multidisciplinary teams with expertise at all phases of the product development process, such as design, process, production, marketing, production, etc. Multidisciplinary teams may break down barriers and create efficient ways of communication across departments.

\subsubsection{Communication}

In order to succeed in the CE, communication is vital. Teams will operate more effectively if they know what other members do. Team members meet regularly to facilitate quick and effective information sharing (Kusar et al., 2004). In the early stage of product development process, communication between vendors, customres and producers is also a 


\section{International Advanced Research Journal in Science, Engineering and Technology}

Vol. 8, Issue 6, June 2021

DOI: $10.17148 /$ IARJSET.2021.8693

fundamental concept in implementing the CE (Portioli-Staudacher et al., 2003; Hamid et al., 2005) [2]. But less communication might lead to less time, and less misunderstanding, according to Bhuiyan et al. (2006).

\subsubsection{Management Support}

The primary difficulty in the course of CE practise was management's commitment to implementing CE according to Abdulla (1999).

The leadership and assistance of the senior management in implementing a successful CE is therefore crucial. The senior managers not only should support the CE initiative but also engage actively in the development and implementation of the CE objectives.

\subsubsection{Suppliers and Customers Participation}

The integration between customers, suppliers and manufacturers is crucial when developing and producing a product to determine the success of a product. This CE concept may, in the early stage of product development, avoid a substantial amount of design errors and redresses as a result of misunderstandings or misunderstandings between the firm, customer and supplier.

\subsection{Process}

A single well-defined process with a clear ownership and goals is a crucial in the implementation of the CE method. Therefore, the process and the associated calendar of events must be founded on certain fundamental concepts:

\subsubsection{Work structure}

All product-development efforts in general should be conducted simultaneously and in tandem. In order to develop a clear work structure or framework some components must be expressly specified, such as creating and formalising the CE process, specifying key duties and identifying process ownership.

\subsubsection{Early Problem Discovery}

Problems found early on in the product development process (especially within the first $20 \%$ of the cycle period) can be resolved more easily than those uncovered later [2].

\subsubsection{Making an Initial Decision}

The 'window of opportunity' in the design phase is far broader than in a later phase, i.e. when some of the choices are locked and the design is developed.

\subsection{Technology and Tools}

To get the greatest benefits that allow integrated product development, a suitable number of tools and technologies should be chosen. The utilisation of tools and technologies is very necessary to achieve efficient CE deployment. However, two things have to be taken into account during the implementation of the tools and technologies: the first is the identification of the tools and technologies that enable an efficient execution of the $\mathrm{CE}$ and the second is the training of persons who use these tools and technologies.

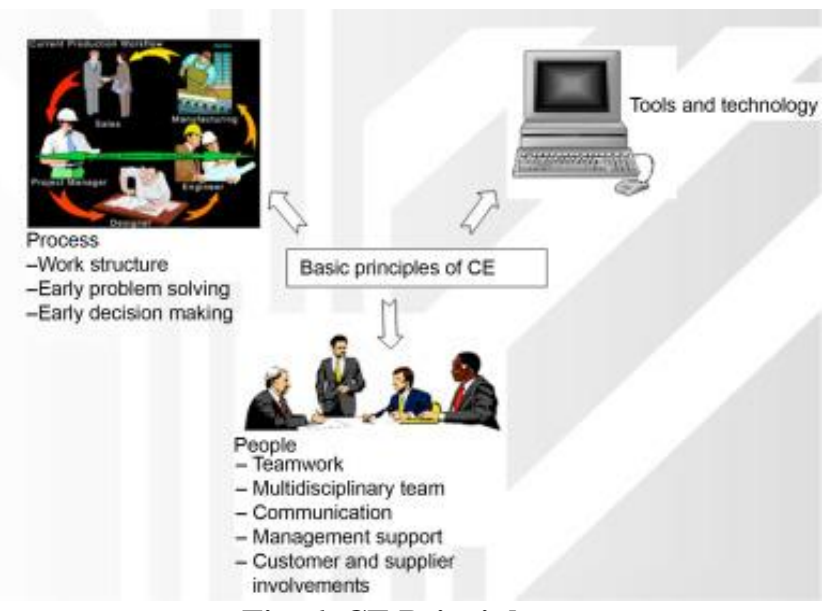

Fig. 6. CE Principles

\section{FUTURE SCOPE}

Engineering is rooted in craftsmanship, in which design and production have genuinely been interwoven. One example is a sled with a traveller creating the product in contact with production ("hits on the sled"). There was then an industrial age of distinct design and production that tended towards sequences and standardised information providers (drawings). Concurrent Engineering is a sequential engineering version that implements handcrafts. The trend is to see a further revolution in engineering. When looking at the content production processes, several forms of knowledge building may be found. It is not parallel, it is not sequential - it is networked. Content production is geared at competency and motivation 


\section{International Advanced Research Journal in Science, Engineering and Technology}

Vol. 8, Issue 6, June 2021

DOI: $10.17148 /$ IARJSET.2021.8693

in knowledge communities and supports knowledge exchange. Efficient communication is the fundamental infrastructure through the use of networks.

\section{APPLICATIONS}

\subsection{Medium to Large Enterprises}

In the current financial situation, responding swiftly to the business issues for medium and big businesses is the most essential task.

Global business management is needed for medium-sized and big firms, either to increase the client base or to obtain more cost-effective resources. In this circumstance concomitant engineering is used to preserve its advantageous market position and meet the difficulties. Competitive engineering allows companies to use:

a) Manage the complexity of product design and development.

b) Control costs and supply of the product to be used for least costs.

c) Manage new product launch.

d) Accelerate the customising process.

e) Providing a product reuse platform.

\subsection{Small to Medium Enterprises}

Small and medium-size companies face their limited resources in response to the global issues. One needs a pre-defined, best-in-class approach to effectively meet your client demands. The biggest benefits for them are concomitant engineering with the best practises of the industry. Simultaneous engineering methods allow them to:

a) Low cost ownership sustainability.

b) Enhance their reuse.

c) Efficiency improvement through simple design review and good management of change.

d) Education about mistakes through better cooperation across many departments.

e) Make fast tailored market demand response.

\section{INDUSTRIAL IMPACT}

The business model in the manufacturing sector has moved from "modelling," to "built-to-order," to "build-to-order" and "innovative to-order" business. The influence of competitor engineering should be validated on the industrial platform in this quickly changing industrial atmosphere. The technology may be used in many industries, market-placed, technologydriven, production-driven, and project-driven industries. Various simultaneous engineering solutions fit into various industries with distinct features. That demonstrates the enormous potential for concurrent engineering solutions to satisfy industrial requirements. Due to the application of concurrent engineering methodologies, expected potential benefits for the various industries are:

a) The design chain includes customers.

b) More pleasure for customers can be attained.

c) During the design and development stage over 70 per cent of the product costs are included.

d) Designer, producer, provider and consumer can share views about the product.

e) During the design process, cost and profit margin may be established.

f) The design group primarily supports feedback from suppliers with market experience [3].

g) Better production with a lower cycle time and cost reduction.

\section{CONCLUSIONS}

The needs of the market and customers provide excellent products at cheap costs in time. The use of the latest technology provides us with the benefit, however, that the organisational profitability of high quality products is not as high and hence growth rates are modest. With the installation of the competing engineering organisations, profit from any single product is beneficial. Teamwork is the foundation of the CE. The essay focuses on teamwork and training, the structure and team organisations in small and medium-sized enterprises.

\section{REFERENCES}

1. Basu et al., A Study on Concurrent Engineering-Based Design and Product Development, International Journal of Recent advances in Mechanical Engineering (IJMECH) Vol.2, No.1, February 2013.

2. Hambali et al., The Important Role of Concurrent Engineering in Product Development Process, ISSN: 0128-7680, Pertanika J. Sci. \& Technol. Vol. 17 (1) 2009

3. Ganeshappa K. "Production and Prospects of Agriculture -A case Study of Shimoga District of Karnataka". International Research Journal on Advanced Science Hub, 2, Special Issue ICSTM 12S, 2020, 111-115. doi: 10.47392/irjash.2020.271

4. Sowmya Dhanalakshmi.C; Madhu P; Hemachandran N; Bharathkumaran G; Harisharvinth LB. "Design and fabrication of four-way hacksaw machine - A design thinking approach". International Research Journal on Advanced Science Hub, 2, 7, 2020, 126-130. doi: 10.47392/irjash.2020.76 


\section{International Advanced Research Journal in Science, Engineering and Technology}

Vol. 8, Issue 6, June 2021

\section{DOI: $10.17148 / I A R J S E T .2021 .8693$}

5. Aniket U. Dongre et al., Concurrent Engineering: A Review, International Research Journal of Engineering and Technology (IRJET) e-ISSN: 2395 -0056, p-ISSN: 2395-0072

6. X. G. Ming et al., Concurrent Engineering: Research and Applications, Technology Solutions for Collaborative Product Lifecycle Management Status Review and Future Trend

7. David Juarez et al., Concurrent Engineering applied to key industrial sector, annals of the university of oradea, Issue 3, 2015

8. M. Lawson et al., "A Survey of Concurrent Engineering," Concurrent Engineering Research and Applications, Vol. 2, No. 1, 1994.

9. Naval Surface Warfare Centre, A Report on Concurrent Engineering Implementation in a Shipyard, Nov. 1995.

10. R.I. Winner et al., "The Role of Concurrent Engineering in Weapons System Acquisition,” Alexandria VA IDA Report R-338, 1988.

11. David Juarez et al., Application of Concurrent engineering product and process design, annals of the University of Oradea, Issue 3 , 2015.

12. Jack Zhou et al., Concurrent Engineering Concepts Applied to Concurrent Education and Research, International Conference on Concurrent Engineering, Research and Applications (CE96/ISPE), August 1996.

13. Andrew Kusiak, Concurrent Engineering-Automation, Tools, and Techniques, John Wiley \& Sons, 1993.

14. M. Young, The Technical Writer's Handbook. Mill Valley, CA: University Science, 1989.

15. D. K. Pawar et. Al., "Concurrent Engineering: From Concept to Implementation," presented at the International Conference on Agile Manufacturing, Bangalore, 1996.

16. Jian, G., Oriet, L., Understanding and Implementation of Concurrent Engineering. The Proceedings of the 11th International Conference on Concurrent Enterprising. Munich, Germany, June 2005.

17. Yanjun Qian et al., Recent Advances in Concurrent Engineering Modeling, 5th International Asia Conference on Industrial Engineering and Management Innovation (IEMI 2014), pp.6-9, 2014 